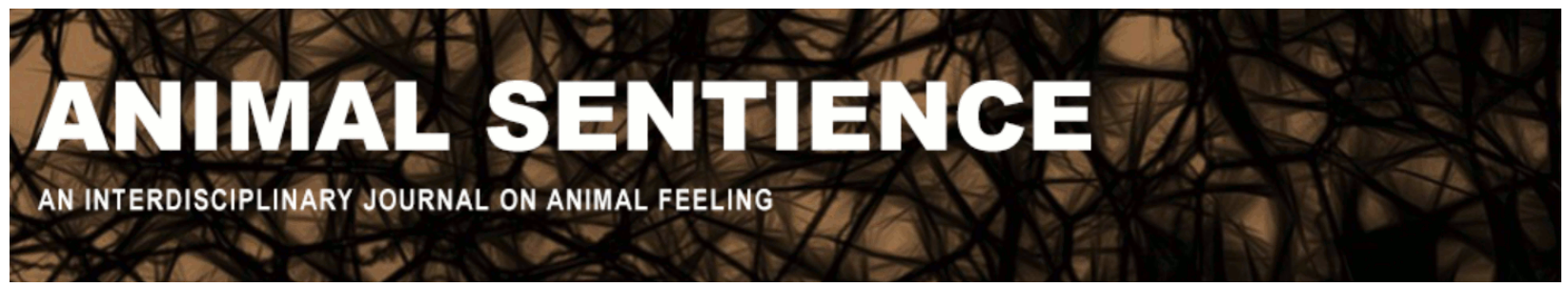

Silver, Zachary A. and Santos, Laurie R. (2018) Understanding dogs' neural responses in a food-giving paradigm. Animal Sentience 22(15)

DOI: $10.51291 / 2377-7478.1346$

Date of submission: 2018-06-10

Date of acceptance: 2018-06-13

(c)

This article has appeared in the journal Animal

Sentience, a peer-reviewed journal on animal

cognition and feeling. It has been made open access,

free for all, by WellBeing International and deposited

in the WBI Studies Repository. For more information,

please contact

wbisr-info@wellbeingintl.org.

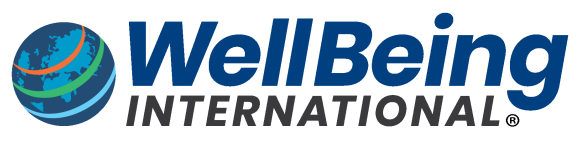

SOLUTIONS FOR PEOPLE, ANIMALS AND ENVIRONMENT 


\title{
Understanding dogs' neural responses in a food-giving paradigm
}

\author{
Commentary on Cook et al. on Dog Jealousy
}

\author{
Zachary A. Silver \& Laurie R. Santos \\ Department of Psychology \\ Yale University
}

\begin{abstract}
In their target article, Cook et al. provide exciting new insights into dogs' neural responses when they watch their caregivers giving food to a fake dog or placing it into a bucket. The use of $\mathrm{fMRI}$ in awake and unrestrained dogs is tremendously valuable for understanding canine emotionality. We worry, however, that it is too soon to conclude that the reported pattern of amygdala activation corresponds to a specific emotion. Further testing will be essential to determine whether this amygdala activation is indeed an expression of jealousy.
\end{abstract}

Zachary A. Silver is a first-year graduate student at Yale University where he investigates components of social decision making and social learning in nonhuman animals. Prior to beginning his work at Yale, Zachary graduated from Illinois Wesleyan University with a B.A in Psychology and Music.

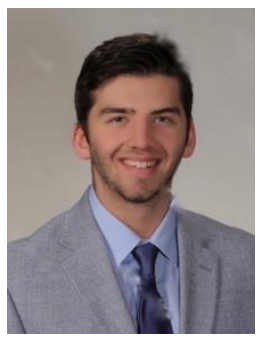

Laurie R. Santos is director of the Comparative Cognition Laboratory and the Canine Cognition Center at Yale. She received her A.B. in Psychology and Biology from Harvard University in 1997 and her Ph.D. in Psychology from Harvard in 2003. She is an Associate Professor in the Department of Psychology. Website

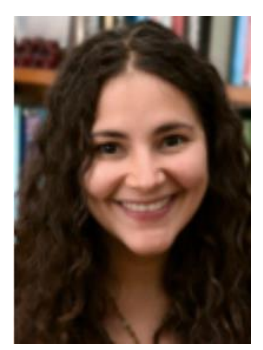

Using a novel noninvasive brain imaging paradigm, Cook et al. (2018) demonstrate that domestic dogs with more aggressive temperaments show increased amygdala activation when watching their caregiver give food to a fake nonspecific compared to when the caregiver places food into a bucket. One exciting feature of this new paper is its use of $\mathrm{fMRI}$ in awake unrestrained dogs. This technique has the potential to provide exciting new insight into areas of canine cognition that are otherwise difficult or impossible to examine empirically. The use of this type of technique will undoubtedly have a tremendous impact on our ability to understand emotion in nonhuman animals. In the present commentary, however, we focus on what the target article tells us about human-like jealousy in dogs today, as we feel the current results introduce almost as many new questions as they provide answers.

Our first question is whether the results provide evidence of human-like jealousy per se in dogs. As the authors note, jealousy in our own species involves a highly complex set of emotions. Before concluding that the observed pattern of amygdala activation in aggressive dogs is indicative of jealousy, we must rule out alternative explanations. For example, could the observed 
increase in amygdala activity indicate not jealousy but some other phenomenon? It is to be expected that aggressive dogs demonstrate increased amygdala activation when attending to a variety of stimuli that are more socially complex than the bucket control. Under this view, more aggressive dogs show additional amygdala activation not because of the social implications of their caregiver giving food to another dog but simply because this condition involves more complex social stimuli.

Similarly, this pattern of amygdala activation could correspond to fear of the fake dog rather than jealousy. Aggressive dogs may view conspecifics as competitors for resources; under this view, the observed pattern of amygdala activation would indicate not jealousy but a competitive instinct to seek out resources. We were surprised that the authors expected to observe jealousy only in dogs with aggressive temperaments. Humans of all temperaments experience jealousy. It is thus possible that this emotion occurs in dogs with various temperaments.

Overall, we worry that it's too soon to conclude that the reported pattern of amygdala activation corresponds to a specific emotion. Further testing will be essential to determine whether this is indeed an expression of jealousy. To isolate the source of this amygdala activation, future research could investigate whether the pattern of amygdala activation would generalize to other social contexts, and whether the identity of the human performing the action (e.g., a close social partner like a guardian vs. a stranger) affects amygdala activation. Future research should also try to determine whether social resources are important in this effect - as one would expect for the emotion of jealousy - or whether aggressive dogs simply show brain activation indicative of aggression when watching a conspecific in the absence of social resources.

One of the virtues of the fMRI method is the objective nature of the data, free of any subjective human coding errors or biases. To preserve this objectivity, it is important to temper conclusions so as to avoid inadvertent anthropomorphic biases. A holistic investigation of the social and emotional factors involved in jealousy using both neuroimaging and behavioral measures would probably enable us to draw more effective conclusions about the components of jealousy in domestic dogs.

\section{References}

Cook, P., Prichard, A., Spivak, M., and Berns, G. S. (2018) Jealousy in dogs? Evidence from brain imaging. Animal Sentience 22(1) 


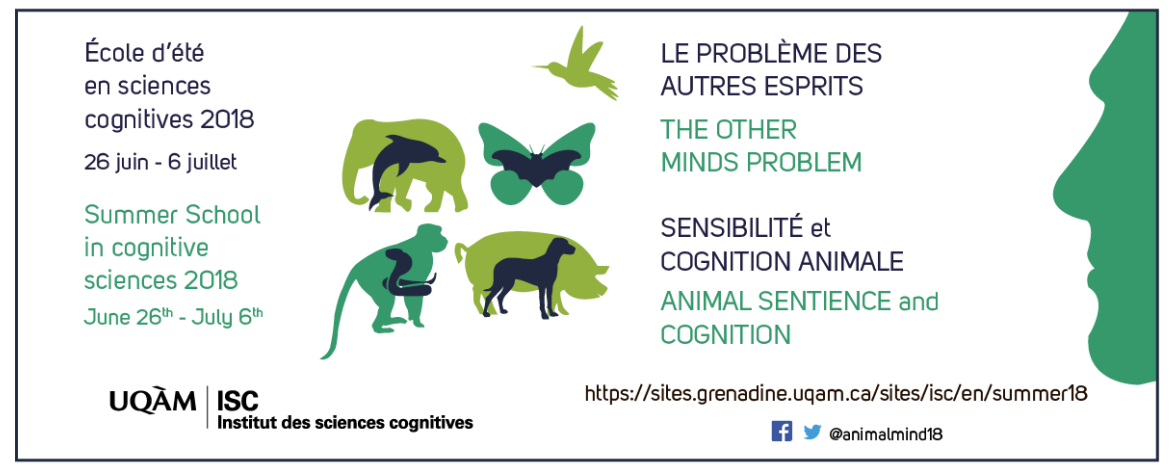

ISC 2018 Summer School in Cognitive Sciences June 26 - July 6, 2018 Montreal (Canada)

\section{The Other Minds Problem: Animal Sentience and Cognition}

Overview. Since Descartes, philosophers know there is no way to know for sure what — or whether — others feel (not even if they tell you). Science, however, is not about certainty but about probability and evidence. The 7.5 billion individual members of the human species can tell us what they are feeling. But there are 9 million other species on the planet (20 quintillion individuals), from elephants to jellyfish, with which humans share biological and cognitive ancestry, but not one other species can speak: Which of them can feel — and what do they feel? Their human spokespersons — the comparative psychologists, ethologists, evolutionists, and cognitive neurobiologists who are the world's leading experts in "mindreading" other species - will provide a sweeping panorama of what it feels like to be an elephant, ape, whale, cow, pig, dog, chicken, bat, fish, lizard, lobster, snail: This growing body of facts about nonhuman sentience has profound implications not only for our understanding of human cognition, but for our treatment of other sentient species

Gregory Berns: Decoding the Dog's Mind with Awake Neuroimaging Gordon Burghardt: Probing the Umwelt of Reptiles

Jon Sakata: Audience Effects on Communication Signals

PANEL 1: Reptiles, Birds and Mammals

WORKSHOP 1: Kristin Andrews: The "Other" Problems: Mind,

Behavior, and Agency

Sarah Brosnan: How Do Primates Feel About Their Social Partners?

Alexander Ophir: The Cognitive Ecology of Monogamy

Michael Hendricks: Integrating Action and Perception in a Small

Nervous System

PANEL 2: Primates, Voles and Worms

WORKSHOP 2: Jonathan Birch: Animal Sentience and the

Precautionary Principle

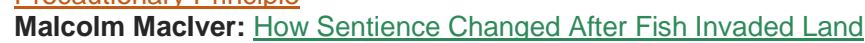
385 Million Years Ago

Sarah Woolley: Neural Mechanisms of Preference in Female

Songbird

Simon Reader: Animal Social Learning: Implications for

Understanding Others

PANEL 3: Sea to Land to Air

WORKSHOP 3: Steven M. Wise: Nonhuman Personhood

Tomoko Ohyama: Action Selection in a Small Brain (Drosophila

Maggot)

Mike Ryan: "Crazy Love": Nonlinearity and Irrationality in Mate Choice Louis Lefebvre: Animal Innovation: From Ecology to

Neurotransmitters

PANEL 4: Maggots, Frogs and Birds: Flexibility Evolving

SPECIAL EVENT: Mario Cyr: Polar Bears

Colin Chapman: Why Do We Want to Think People Are Different?

Vladimir Pradosudov: Chickadee Spatial Cognition

Jonathan Balcombe: The Sentient World of Fishes

PANEL 5: Similarities and Differences

WORKSHOP 5 (part 1): Gary Comstock: A Cow's Concept of Her

Future

WORKSHOP 5 (part 2): Jean-Jacques Kona-Boun: Physical and Mental Risks to Cattle and Horses in Rodeos
Joshua Plotnik: Thoughtful Trunks: Application of Elephant Cognition for Elephant Conservation

Lori Marino: Who Are Dolphins?

Larry Young: The Neurobiology of Social Bonding, Empathy and

Social Loss in Monogamous Voles

Panel 6: Mammals All, Great and Small

WORKSHOP 6: Lori Marino: The Inconvenient Truth About Thinking Chickens

Andrew Adamatzky: Slime Mould: Cognition Through Computation Frantisek Baluska \& Stefano Mancuso: What a Plant Knows and Perceives

Arthur Reber: A Novel Theory of the Origin of Mind: Conversations With a Caterpillar and a Bacterium

PANEL 7: Microbes, Molds and Plants

WORKSHOP 7: Suzanne Held \& Michael Mendl: Pig Cognition and Why It Matters

James Simmons: What Is It Like To Be A Bat?

Debbie Kelly: Spatial Cognition in Food-Storing

Steve Phelps: Social Cognition Across Species

PANEL 8: Social Space

WORKSHOP 8: To be announced

Lars Chittka: The Mind of the Bee

Reuven Dukas: Insect Emotions: Mechanisms and Evolutionary

Biology

Adam Shriver: Do Human Lesion Studies Tell Us the Cortex is

Required for Pain Experiences?

PANEL 9: The Invertebrate Mind

WORKSHOP 9: Delcianna Winders: Nonhuman Animals in Sport and Entertainment

Carel ten Cate: Avian Capacity for Categorization and Abstraction

Jennifer Mather: Do Squid Have a Sense of Self?

Steve Chang: Neurobiology of Monkeys Thinking About Other

Monkeys

PANEL 10: Others in Mind

WORKSHOP 10: The Legal Status of Sentient Nonhuman Species 